\title{
Overcoming Breastfeeding Challenges: A Qualitative Inquiry
}

Share this: fis
Debra Rose Wilson, Ph.D., MS, RN, IBCLC, RLC, AHN-BC CHT ${ }^{1}$

Cathy Cooper, Ed.D., MSN, RN, $\mathrm{CNE}^{2}$

Kristi Plunk, MSN, RN ${ }^{3}$

Mariesa Severson, MSN, RN, WHNP ${ }^{4}$

Breastfeeding duration rates continue to fall short of recommended targets. Weaning that is earlier than the mother intended likely occurs when she encounters a challenge that she could not overcome. It is not clear from existing studies why some women overcome challenges while others do not. This qualitative phenomenological study asked, "What is the lived experience of overcoming breastfeeding challenges?" Three themes emerged through grounded-theory data analysis. Anticipatory Guidance instilled hope and knowledge, and identified potential resources, all of which assisted with overcoming the challenges. Breastfeeding is complexly interwoven with Maternal-Role Attainment. Resilience provides protective factors when one is challenged. Theory arising from these themes has implications for both practitioners and researchers. This study illustrates concrete strategies to enhance maternal-role attainment and ensure desired duration of breastfeeding.

Keywords: Challenges, breastfeeding, resilience, duration, early weaning, qualitative, Parse Clinical Lactation, 2012, Vol. 3-4, 155-160

Breastfeeding is a proactive and cost-effective way of reducing global rates of child mortality and morbidity. More mothers in North America are choosing to breastfeed. Initiation rates are increasing but duration rates are not increasing as rapidly as hoped. The purpose of this qualitative study was to examine and describe the lived experience of women who initiated breastfeeding, overcame challenges in the process, and continued to breastfeed successfully. Application of theory developed from these findings may provide avenues to increase the ability of mothers to overcome breastfeeding challenges.

The Centers for Disease Control and Prevention (2012) report $81.9 \%$ of U.S. mothers initiated breastfeeding, with $60.6 \%$ still breastfeeding at 6 months. Approximately $46.2 \%$ of babies are exclusively breastfed through three months, and $25.5 \%$ are exclusively breastfed through six months. Health Canada (2012) reports that $87.9 \%$ of mothers initiate breastfeeding and rates are steadily rising. National and global initiatives have contributed to a steady increase in these indicators over the past five years. Breastfeeding-friendly hospitals, workplaces, and communities have developed programs to educate and facilitate breastfeeding. However, many hospitals have policies that do not conform to the WHO code and may interfere with a mother's success (CDC,

1. Debrarosewilson@comcast.net, Middle Tennessee State University, Walden University

2. Cathy.cooper@mtsu.edu, Middle Tennessee State University

3.Kristina.Plunk@mtsu.edu, Middle Tennessee State University

4. Mariesa.Severson@mtsu.edu, Middle Tennessee State University
2012). To compound this, duration rates are lower than desired and likely even lower than reported (Agampodi et al., 2011; Chalmers et al., 2009).

Most health authorities recommend breastfeeding exclusively for up to six months, with continued breastfeeding for two years or longer. Women often discontinue breastfeeding before intended, but there are other mothers who face these same challenges, overcome them, and continue to breastfeed (Li et al., 2008). While it seems obvious mothers with previous breastfeeding experience should breastfeed longer, studies have found parity does not influence the overall duration of breastfeeding (Ladomenou et al., 2007).

The duration of breastfeeding is influenced by education and age of the mother, prenatal intent, race, and social support (Pollard \& Guill, 2009). Factors that influence the decision to discontinue breastfeeding include availability of formula, perception of inadequate supply, prematurity, lack of social support, cultural acceptance, and return to work (Pollard \& Guill, 2009). The existing literature, however, does not clearly identify what intrinsic or extrinsic factors differentiate the mother who gives up breastfeeding when challenged from the mother who overcomes the same challenge and continues to successfully breastfeed. By understanding the process and factors contributing to success, healthcare providers can better predict challenges, identify mechanisms to motivate and support the mother, and decrease the rate of early weaning. 
This study was guided by phenomenology, existentialism, and Parse's theory of Human Becoming. Phenomenological theory is driven by the belief that the subjective life experience is the relevant definition of personal reality. Phenomenology describes the structure of the subjective experience as presented to consciousness (Husserl, 1965). Existentialist enquiry tends to focus on the characteristics of ontology, or modes of being (Sartre, 1993). The phenomenological approach is congruent with the practice of lactation consulting because of the holistic focus on the human experience (Parse, 1998). Parse's mid-range nursing theory of Human Becoming emphasizes perception and meaning from the patient's perspective, and recognizes the patient's responsibility for making informed choices (Parse, 1997, 1998). Meaning arises from the exchange of the human with all that is surrounding, and defines life.

\section{Method}

A qualitative phenomenological design was used to examine the lived experience of overcoming breastfeeding challenges. IRB approval and informed consent were obtained. Seventeen mothers who overcame breastfeeding challenges were interviewed and audiotaped. Interviews were open-ended, lasted from 45 to 65 minutes, and were conducted by the same IBCLC researcher trained in qualitative interviewing and true presence.

The participant was encouraged to tell the story of her breastfeeding experience, the challenges she faced, the strategies used to overcome challenges, the personal qualities employed, the transcendence through the experience, and the resultant meaning found in the experience. Verbatim transcripts were analyzed using grounded theory, an inductive approach to explore patterns and generate theory. After data analysis and model development, two independent practitioners took the model to mothers who overcame breastfeeding challenges and verified the model as valid and reflective of their experience.

\section{Findings}

Demographic data collected from the 17 participants reflected an age range of 20 to 34 years, with a mean of 28 years. Sixty-five percent (11) of the participants were primipara, and $35 \%$ (6) were multipara. Annual household income ranged from less than $\$ 15,000$ to $\$ 150,000-\$ 249,000$, with a median of approximately $\$ 52,000$. The mean age of the baby at the time of the interview was 12 months, with a minimum of 5 months and a maximum of 23 months. The majority of the participants $13(76 \%)$ were Caucasian, 2 (18\%) were Hispanic, and 2 (18\%) were African American. Seven participants (41\%) had completed some college, 6 (35\%) were high school graduates, 3 (18\%) had bachelor degrees, and $1(1 \%)$ had completed some high school.

Three themes emerged from the categories and codes generated by the data. These themes included: 1) Anticipatory guidance; 2) Breastfeeding as complexly intertwined with maternal-role attainment; and 3) Resilience. Theory generated from this study describes how the anticipation and perception of success in breastfeeding influences the experience and is reflective of learned and innate resilience to overcoming breastfeeding challenges.

\section{THEME 1: Anticipatory Guidance}

Participants, whether primaparas or multiparas, drew upon guidance, resources, and teaching they had obtained prior to delivery. Most mothers had sought out education through formal means, such as breastfeeding classes, or through less-formal means, such as the internet, friends and family, and reading books on the subject.

My confidence might be higher than other women who didn't go to breastfeeding classes. I just expected to be able to do this, 'cause that's what I learned in the classes. I can do this; I will make enough milk for my baby. A mom who doesn't have that confidence might give up easier.

Regardless of the source of prenatal education and support, mothers reported a connection they had made that gave them confidence, which encouraged their expectation and resolve to overcome the challenge. Mothers reported being more tenacious with problem solving, and actively seeking out more problem solving approaches when previous strategies had failed.

When I still had troubles latching the baby after all the help already, I still just KNEW that I could do this. I kept digging into the resources, finding new ones, then finally finding a Lactation Consultant who could break it down for me and teach me the movements. My aunt kept telling me this was why she had given up breastfeeding, and it was $\mathrm{OK}$ if he [the baby] needed a bottle. It wasn't like I was her. I was like a dog with a bone, and I wasn't giving up.

The mother's expectation of success played a part in overcoming challenges. Support systems were in place prior to delivery, which allowed more efficient access to help. The participants valued advice from nurses, family, 
and friends who had successfully breastfed. They reported actively seeking help early when problems arose.

I was not going to tolerate these really sore nipples for very long. I knew it wasn't supposed to hurt so bad. I called [sister] and she got me to call for help right away.

Anticipatory guidance was first introduced in mental health education in the early 1930s. Using anticipatory guidance as a primary intervention, healthcare providers can alleviate stress and apprehension. Support, skill development, and informational needs are met by providing preemptive information so that role mastery can occur (Hill et al., 1994). A prenatal education program that includes one-to-one education, behavioral and skill development counseling, and breastfeeding classes, is the single most effective primary intervention to increase initiation and duration of breastfeeding (Keister et al., 2008). When partners and family of the childbearing women were included in the education, it further increased the mothers' sense of support and confidence.

\section{THEME 2: Breastfeeding Is Complexly Intertwined with Maternal-Role Attainment}

Kitzinger (1987) first described the experience of breastfeeding in a holistic framework to provide anticipatory guidance for the lactating mother.

Mechanical failure and difficulties with breastfeeding at the physiological level cannot be isolated from the psychological aspects of lactation, and psychology is interlocked with social factors... (p. 198).

The embodied experience of breastfeeding was seen as fundamental to the definition of motherhood.

If I couldn't feed my baby, what was I doing trying to have a baby? ... not just as a failure at breastfeeding, but that meant I sucked as a mother too. I know that's extreme, but that's how you hear it when you are all upset.

Mercer introduced the concept of maternal-role development in the early 1960s. Later Rubin introduced it in middle-range theory (Tarkka, 2003). Maternal-role development is primarily a cognitive process, highly interacting with social aspects of culture and family that influences development as a mother. Feedback from people in women's support networks validates their competence, and mothers' success is influenced by the expectations of others (Tarkka, 2003). A statement that breastfeeding will be successful, and setting an expectation for overcoming any challenges, should be common practice for those educating, assisting, or supporting the childbearing family.

My heart just sunk when I was encouraged to quit breastfeeding by well-meaning family.... This [breastfeeding] was something that only I could do for my baby, and I didn't want that taken away from me .... I wanted that special connection, that made me feel like I was the only one who could care for my baby ... this was my baby and this was what I was supposed to do.

\section{THEME 3: Resilience}

Resilience, the third theme identified from the data, is characterized by positive adaptation and is:

the capacity to rebound from adversity, strengthened and more resourceful. It is an active process of endurance, self-righting, and growth in response to crisis and challenge (Walsh, 2006, p. 4).

In general, resilience is defined in terms of a person's capacity to adapt and/or persevere despite difficult circumstances. This perseverance is a capacity to withstand stressors without psychological dysfunction. Resilience is built and improved upon with the development of new coping skills. It is a dynamic quality, closely related to hardiness, resourcefulness, self-efficacy, and self-confidence. Resilient individuals possess a particular set of attitudes, as well as the cognitive and emotional skills necessary to adapt, survive (and perhaps even thrive) in the midst of hardship or adversity. Resilient individuals view challenges as opportunities, manage a variety of situations competently, possess faith with deeply rooted meaning, and have a healthy support network. Resilience enables people to find the determination to meet and overcome challenges in the midst of overwhelming events. Strategies for developing or improving resilience include developing positive and strong relationships with friends and family, identifying a purpose for one's life, building on the skills and strategies from previous experiences that were successful in overcoming difficulties, and engaging in self-care activities, such as regular exercise, adequate sleep, and eating a healthy diet (Mayo Clinic Staff, 2009).

A strong sense of coherence and resilience enhances existing coping skills, acts as a buffer to adversity, and contributes to an understanding that challenges are to be expected. Previous studies have demonstrated a significant relationship between self-efficacy and 
breastfeeding success (Pollard \& Guill, 2009). Pollard and Guill (2009) identified self-efficacy as a modifiable factor to reduce early weaning. Women with a higher perceived self-efficacy tended to persist even through challenges. Women with lower self-efficacy or selfconfidence may wean earlier than they intended. Some will avoid challenges if they feel they do not have the skills to cope. While Pollard and Guill's study is a great beginning to examining modifiable risk factors, selfefficacy is only one of numerous factors that contribute to resilience.

Even though it took a while to get through that, and I wanted to quit, I knew I had what it took...to keep trying.

There may be some predictive value to screening for selfefficacy and resilience. At-risk populations would benefit from intentional targeting of education and support. In the resilience literature, there has been little attention devoted to ethnically diverse populations and socioeconomic differences. There were no specific differences noted between populations in this qualitative study, but the role of racial socialization in the development of resilience has been well established (Terzian \& Harriott, 2010). Healthcare providers would benefit from a culturally diverse perspective when assessing or fostering resilience behaviors.

The concept of resilience was previously studied only within the domain of psychology. There is a trend towards more multidisciplinary use of resilience as a research construct, although there were no published studies found that examined resilience as a factor in breastfeeding. Focus on enhancing resilience, as a characteristic malleable to support, education, and anticipatory guidance, is within the realm of practice for lactation consultants, nurses, midwives, and childbirth educators.

\section{Generated Theory}

Figure 1 illustrates the concepts and themes associated with overcoming breastfeeding challenges. Anticipatory guidance was a significant factor in generating hope, building a knowledge base, and lining up potential resources for support. Successful attainment of the maternal role is complexly integrated into successful breastfeeding; the belief that breastfeeding defined good mothering provided more motivation to overcome challenges. Resilience was a protective factor also fed by hope, knowledge, and resources.

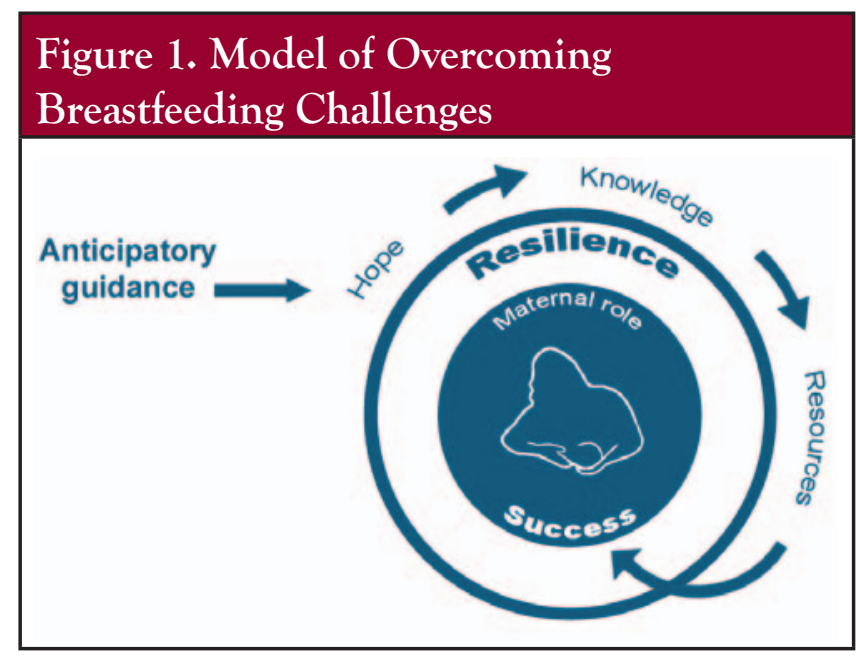

\section{Limitations}

Generalization about the meaning of breastfeeding cannot be derived from a small sample. This study was intended to suggest likely avenues of inquiry for further research. Exploring the meaning of overcoming challenges and successfully breastfeeding opens up the door to other paradigms of thought.

\section{Recommendations}

Further research is needed to test theory derived from the current data. Quantitative data should be gathered on personality types, resilience, instillation of hope, and other objectively measured characteristics to determine which of these factors are relevant to overcoming breastfeeding challenges. Expanded studies could compare the characteristics of those who weaned by choice to those mothers who weaned before personal goals were met. New data may further validate meaning and theory that emerged when exploring the lived experience of successful breastfeeding. It is clear that anticipatory guidance about breastfeeding improves outcomes. Inexpensive educational strategies during prenatal care, as well as a pre-conception normalization of successful breastfeeding, will have an impact on increasing duration of breastfeeding.

Unintentional weaning often happens within the first weeks postpartum. During this critical period, developing support systems would help increase duration of breastfeeding. Identification of those mothers who may be at risk for stopping breastfeeding early would help steer program funds to appropriate recipients. Early maternal reemployment has been associated with increased weaning (Ladomenou et al., 2007). Systems of support in the workplace to promote breastfeeding 
should be acknowledged and rewarded by professional and parenting groups.

Not only is patient education important, but education and support of healthcare providers is warranted. Continued support, education, and resources will add to successful breastfeeding and have an impact on achieving Healthy People 2020 targets of longer breastfeeding duration.

\section{Conclusions}

Readers are not going to be surprised that mothers who overcame breastfeeding challenges reported being well prepared and organized with anticipatory guidance. Resources were in place if needed, and support systems were readily accessed. Breastfeeding is a holistic, lived experience, one that participants perceived as integral to the experience of motherhood. A health professional's approach to assisting breastfeeding mothers needs to be accurate, evidence-based, and holistic in approach. Anticipatory guidance prenatally and in the immediate postpartum period should provide information about common lactation problems, suggestion of strategies and resources to overcome these problems, and instillation of hope with an expectation of successful breastfeeding. Similar to previous work, these results support the value of identifying predicting factors for early weaning, and providing anticipatory guidance, knowledge, resources, and hope. This study describes the lived experiences of 17 mothers who successfully overcame challenges to breastfeeding. May their stories serve as a powerful example of resilience, a reminder to offer anticipatory education, and a source of encouragement for other women persevering through difficulties.

\section{References}

Agampodi, S. B., Fernando, S., Dharmaratne, S. D., \& Agampodi1, T. C. (2011). Duration of exclusive breastfeeding: Validity of retrospective assessment at nine months of age. BMC Pediatrics, 11(80), 1-5. Retrieved from: http://www.biomedcentral. $\mathrm{com} / 1471-2431 / 11 / 80$

Centers for Disease Control and Prevention [CDC]. (2011). Vital signs: Hospital practices to support breastfeeding--United States, 2007 and 2009. Morbidity and Mortality Weekly Report, 60(30), $1020-1025$.

Centers for Disease Control and Prevention [CDC]. (2012). Breastfeeding Report Card-United States, 2011. Retrieved from: http://www.cdc.gov/breastfeeding/data/reportcard.htm
Chalmers, B., Levitt, C., Heaman, M., O’Brien, B., Sauve, R., Kaczorowski, J., Maternity Experiences Study Group of the Canadian Perinatal Surveillance System, \& Public Health Agency of Canada. (2009). Breastfeeding rates and hospital breastfeeding practices in Canada: A national survey of women. Birth, 36(2), 122-132.

Health Canada. (2012). Breastfeeding data. Retrieved from: http:// www.hc-sc.gc.ca/index-eng.php

Hill, P., Humenick, S., \& West, B. (1994). Concerns of breastfeeding mothers: The first six weeks postpartum. Journal of Perinatal Education, 3(4), 47-58.

Husserl, E. (1963). Phenomenology and the crisis of philosophy. (Q. Lauer, Trans.) New York: Harper and Row.

Keister, D., Roberts, K. T., \& Werner, S. L. (2008). Strategies for breastfeeding success. American Family Physician, 78(2), 225-232.

Kitzinger, S. (1987). The experience of breastfeeding. New York: Penguin.

Ladomenou, F., Kafatos, A., \& Galanakis, E., (2007). Risk factors related to intention to breastfeed, early weaning, and suboptimal duration of breastfeeding. Acta Paediatrica, 96(10), 1441-1444. doi: 10.1111/j.1651-2227.2007.00472.x

Li, R., Fein, S. B. Chen, J., \& Grummer-Strawn, L. M. (2008). Why mothers stop breastfeeding: Mothers' self-reported reasons for stopping during the first year. Pediatrics, 122(Supplement 2), S69 -S76. doi: 10.1542/peds.2008-1315i

Mayo Clinic Staff. (2009). Resilience: Build skills to endure hardship. Retrieved from: http://mayoclinic.com/health/ resilience/MH00078

Parse, R. R. (1997). The human becoming school of thought: A perspective for nurses and other health professionals. Thousand Oaks, CA: Sage Publications.

Parse, R. R. (1998). The human becoming school of thought: A perspective for nurses and other health professionals. Thousand Oaks, CA: Sage Publications.

Pollard, D \& Guill, M. (2009). The relationship between baseline self-efficacy and breastfeeding duration. Southern Online Journal of Nursing Research, 9(4). Retrieved from: http://www. resourcenter.net/images/SNRS/Files/SOJNR articles2/ Vol09Num04Art09.pdf

Sartre, J. P. (1993). Being and nothingness: A phenomenological essay on ontology. (H. W. Barnes, Trans.) New York: Washington Square Press. (Original work published in 1943).

Tarkka, M. (2003). Predictors of maternal competence by first-time mothers when the child is 8 months old. Journal of Advanced Nursing, 4(3), 233-240.

Terzian, M., \& Harriott, V. (2010). From racial discrimination to substance use: The buffering effects of racial socialization. Child Development Perspectives, 4(2), 131-137.

Walsh, F. (2006). Strengthening family resilience. New York: The Guilford Press. 

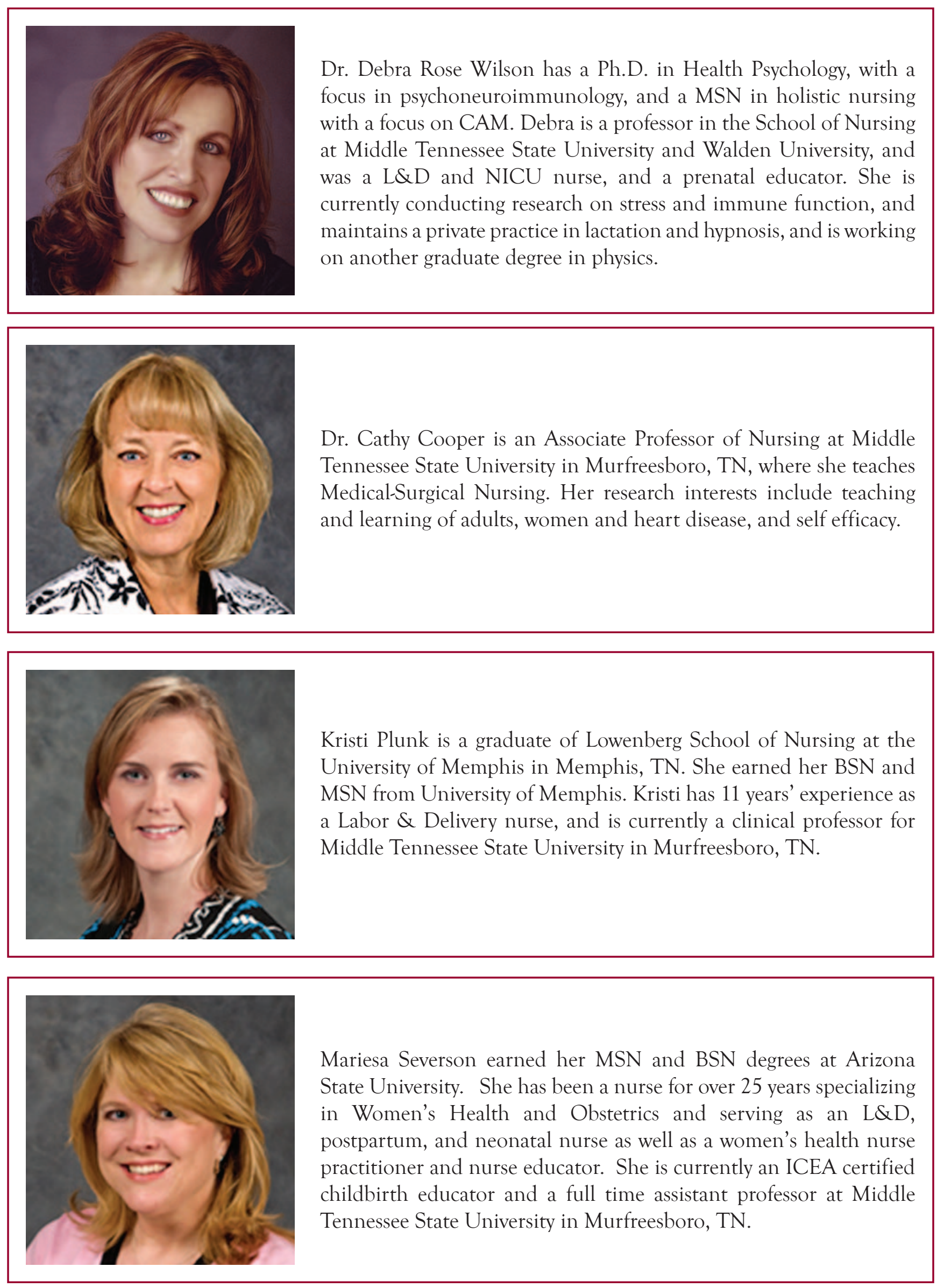


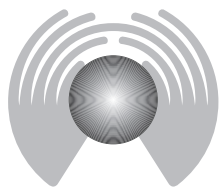

I L C A

International Lactation Consultant Association

United States Lactation Consultant Association

2013 Membership Application

Join online for immediate activation; see website info below.

(Please print clearly)

First Name

Last Name

Address

City

State

Postal Code/Zip Code

Country

Home Phone \#

Business Phone \#

Address Type: $\square$ Home $\square$ Business If Business, Company Name:

*Primary Communication Method for FALC: $\square$ Home \# $\square$ Business \# $\square$ Email
Credentials (12 space max)

IBCLC? \Yes a No

IBCLC Number

Recertification Date

Email

Website

Membership Classifications and Fee Structure (All memberships run January through December)

UNITED STATES - USLCA/ILCA Membership:

Note: the below rates also include membership in the United States Lactation Consultant Association (USLCA). For more info about USLCA, visit www. uslca.org.

ILCA/USLCA Standard

a 1 yr: $\$ 191$

2 yr: $\$ 366$
ILCA/USLCA Contributing Professional*

- 1 yr: $\$ 228$

a 2 yr: $\$ 440$
Mail Payment or Fax form to address at bottom of form.

*Acknowledged in ILCA newsletter.
Directory Listings (ILCA's website has two online directories! Unless you "OPT OUT" below, you will be listed.)

$>$ ILCA has an online Membership Directory (private listing-only ILCA members can view).

I I CHOOSE TO OPT OUT OF THE MEMBERSHIP DIRECTORY

$>$ ILCA members with the IBCLC credential are included in ILCA's online referral directory "Find A Lactation Consultant" (FALC).

*This public listing includes your name, address \& primary contact information.

\section{口 I CHOOSE TO OPT OUT OF THE FALC DIRECTORY}

$>$ Periodically, the ILCA membership address list (no phones or emails) is rented. All mailings are approved by ILCA before the list is rented, to be sure the mailing is of interest to our members.

I CHOOSE TO OPT OUT OF MAILING LISTS RENTALS

\section{Each One Reach One (EORO)}

Who introduced you to ILCA? Would you like the person who invited you to join ILCA to be eligible to earn FREE Conference Registration through our Each One Reach One program? Be sure to list their name here. The awards are given in different categories for those who recruit the most new members. (select only one)

For more info about the EORO program, see

http://www.ilca.org/i4a/pages/index.cfm?pageid=3301

- ILCA Member

- Course Director/Speaker/Educator

Affiliate or Chapter

\section{Charitable Giving}

ILCA Research Grant Fund: used to underwrite research programs in breastfeeding, as chosen by the Research Committee

ILCA General Scholarship Fund: used to cover registration to the Annual conference for an ILCA member demonstrating need

$\$$

General Operating Fund: used to provide additional resources for emergencies and special projects $\bigcirc$ ILCA $\bigcirc$ USLCA

USLCA Licensure Fund: used to support local and state legislative efforts that seek to promote and protect the role of the IBCLC, with the goal to make licensure for IBCLCs the standard

$\$$

Join online for your membership to be active immediately: www.ilca.org/joinonlineus

\section{Payment Information}

Amount Paid \$

Credit Card: $\square$ MasterCard $\square$ Visa $\square$ Discover

Card \#

3-digit security code Exp. Date

Signature

Payment: Must be in US funds.

Mail to: ILCA, 2501 Aerial Center Parkway, Suite 103, Morrisville, NC 27560

OR Fax to: 919-459-2075 

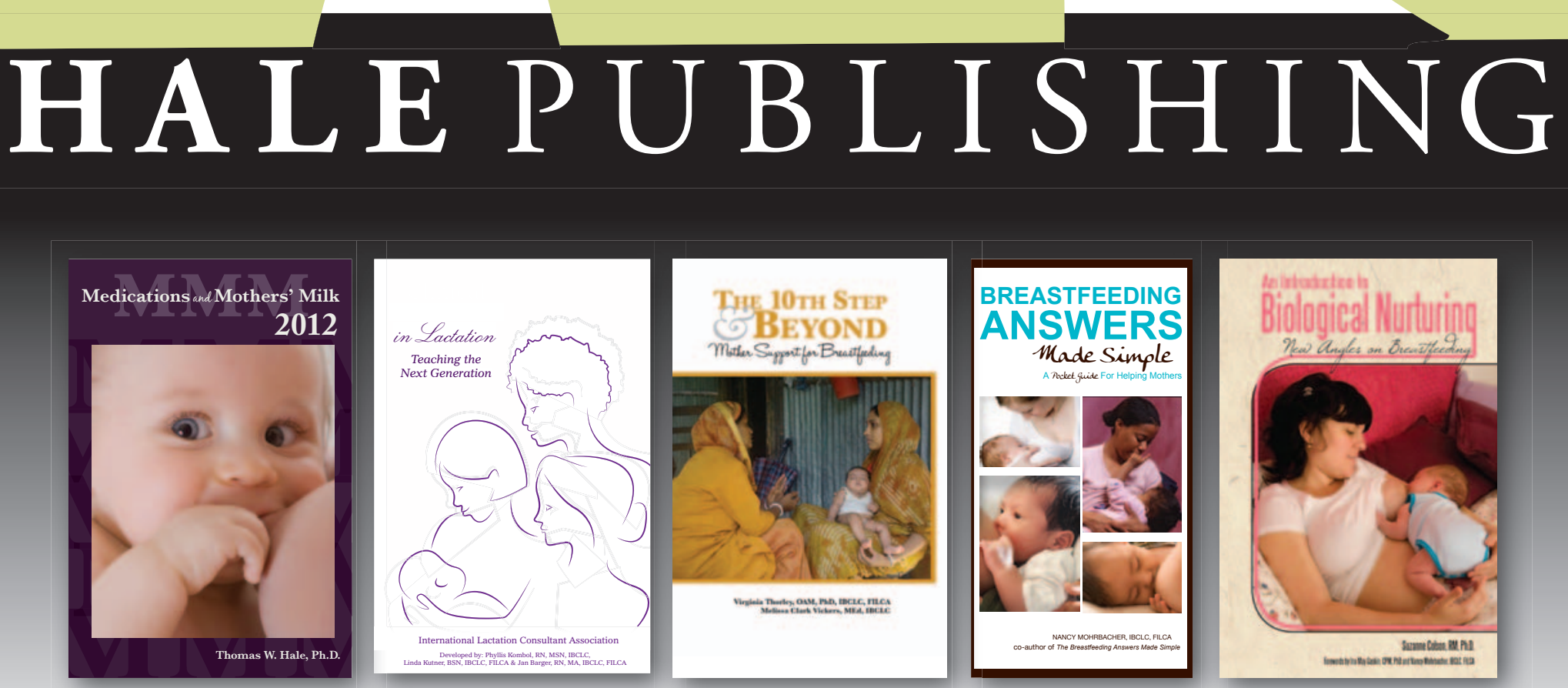

To see more of our books and order online, please visit our website at www.ibreastfeeding.com 


\section{"Best breastfeeding film in decades." Peggy O'Mara / Mothering.com}

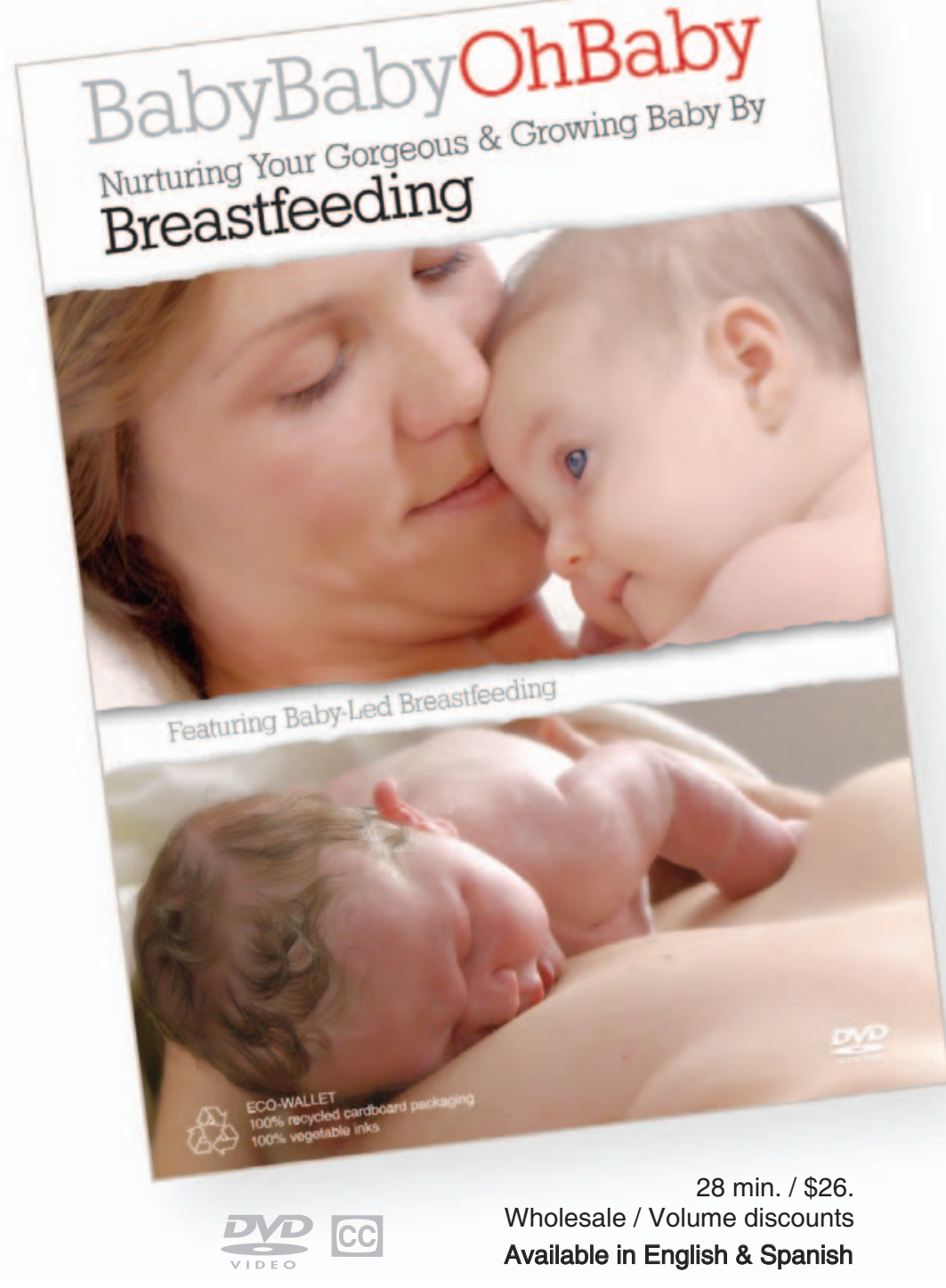

EVERYDAY PRICING

$\begin{array}{llllll}\text { Breastfeeding DVD } & \text { Quantity } & \% \text { Disc. } & \text { Per DVD } & \\ \text { Retail } & 1-5 & & \$ 26.00 & \text { + Shipping } \\ \text { Wholesale } & 6-11 & 40 \% & \$ 15.60 & \text { + Shipping } \\ \text { Wholesale } & 12-249 & 50 \% & \$ 13.00 & \text { FREE Shipping } \\ \text { Wholesale } & 250-4,999 & 60 \% & \$ 10.40 & \text { FREE Shipping } \\ \text { Wholesale } & 5,000-9,999 & 65 \% & \$ 9.10 & \text { FREE Shipping } \\ \text { Wholesale } & 10,000-24,999 & 70 \% & \$ 7.80 & \text { FREE Shipping } \\ \text { Wholesale } & 25,000- & 75 \% & \$ 6.50 & \text { FREE Shipping } \\ & & & & \text { Pricing good thru } 12.31 .12\end{array}$

"Every pregnant mom should watch this to get prepared and excited about what is to come."

\section{Dr. Bill \& Martha Sears}

"BabyBabyOhBaby. Oh my! This is the first breastfeeding DVD to toss out the rules, show the fun, and let the mothers tell the story.

It's eye-candy, it's enthusiastic, it's totally current, and it leaves you wanting to join the breastfeeding sisterhood. BabyBabyOhBaby?

I LoveItLoveItOhLoveIt."

Diane Wiessinger, MS, IBCLC

"This film is magic."

\section{Barbara Emanuel / Executive Director}

La Leche League International

This DVD is designed to inspire, motivate and educate.

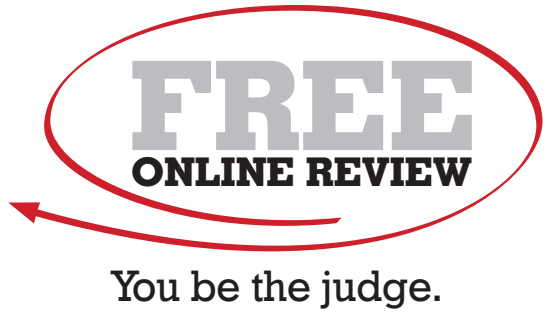

You'll laugh. You'll cry. You'll love it. http://BabyBabyOhBaby.com/CL2012 Exclusively for USLCA members thru 12.31.12
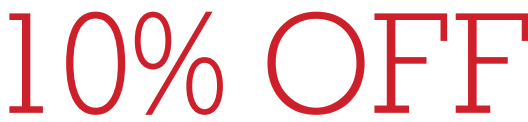

Use coupon code: CL2012 Discount for retail online orders only. Coupon applied to final total. S\&H extra. Expires 12.31.12

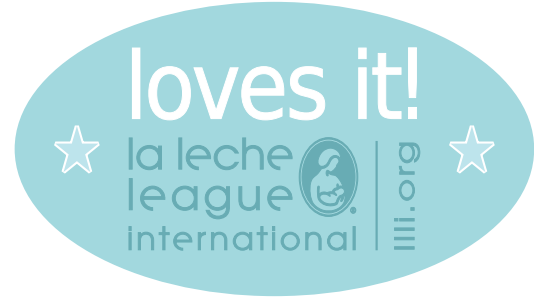

\section{BabyBabyOhBaby.com Incomparable Parenting Videos}




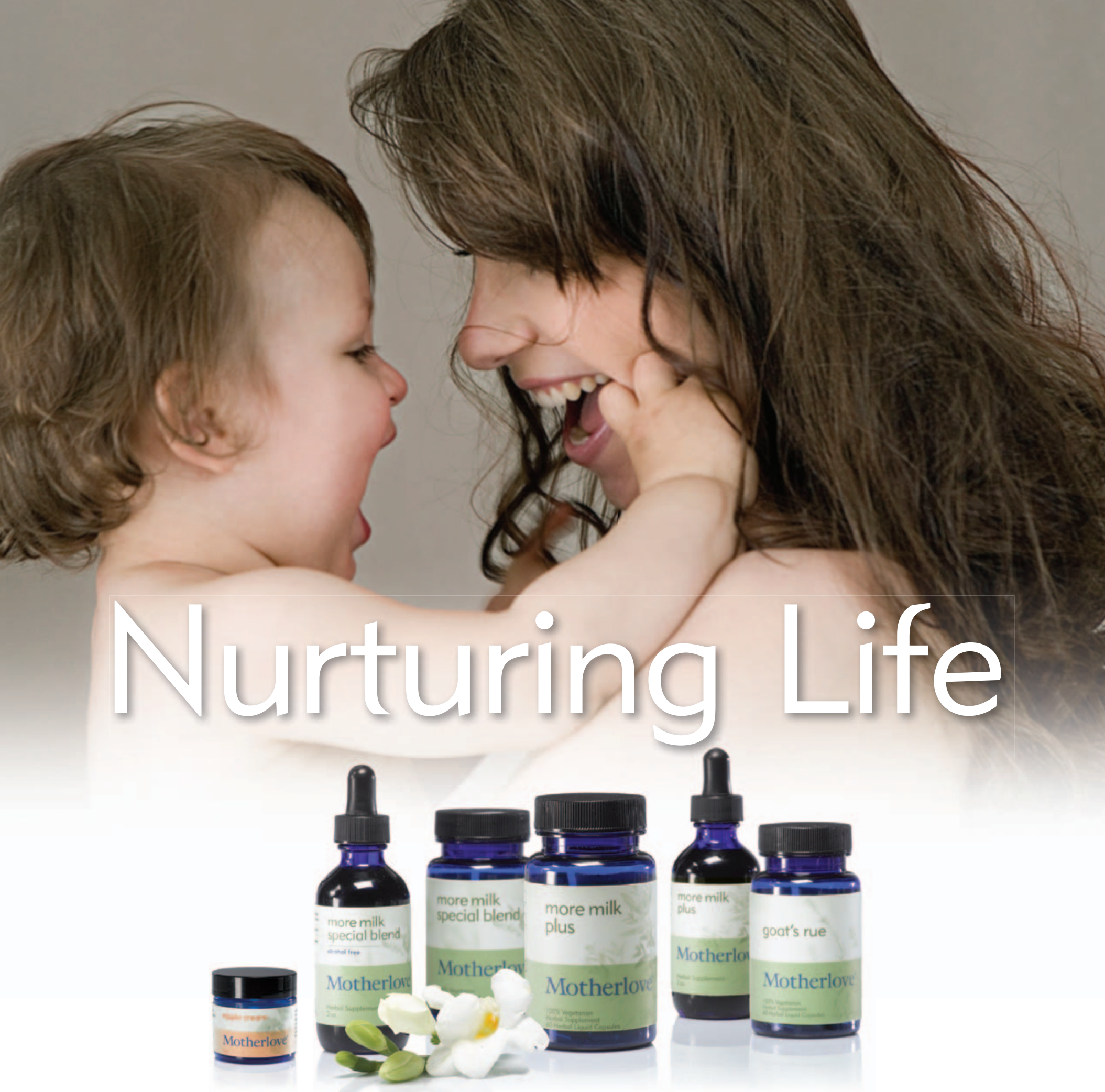

At Motherlove, we believe nothing is more beneficial for mother and baby than breastfeeding.

That is why we are dedicated to making organic herbal products specifically for breastfeeding. In fact, our More Milk Plus is the most trusted and best-selling breastfeeding supplement in the U.S.*

\section{潾Motherlove}

www.motherlove.com $\quad 888-209-8321$ 